\title{
O ENSINO DA AVALIAÇÃO DO PACIENTE: DELINEAMENTO DO CONTEÚDO PELO DIAGNÓSTICO DE ENFERMAGEM*
}

\author{
Cibele Andrucioli de Mattos Pimenta** \\ Diná de Almeida Lopes Monteiro da Cruz** \\ Thelma Leite de Araujo** \\ Kazuko Uchikawa Graziano** \\ Miako Kimura*** \\ Ana Maria Kazue Miyadahira***
}

PIMENTA, C. A. de M., CRUZ, D. A. L. M. de, ARAUJO, T. L. de, GRAZIANO, K. U., KIMURA, M., MIYADAHIRA, A. M. K. O ensino da avaliação do paciente: proposta de delineamento do conteúdo pelo diagnóstico de enfermagem.

O levantamento de dados e o alicerce no qual se fundamenta o cuidado de enfermagem. Na atividade profissional do enfermeiro não está claramente delimitado e nem há consenso sobre quais sejam as entidades clínicas, problemas ou fenômenos que se quer atender. Isso leva a dificuldades em definir quais dados coletar. Esta indefinição está presente no ensino da avaliação do paciente. Acreditando que a determinação dos fenômenos a serem privilegiados direcionam o tipo de dado a ser coletado, as autoras propõem o diagnóstico de enfermagem como estrutura referencial para a coleta de dados do paciente.

UNITERMOS: avaliação, diagnóstico de enfermagem, ensino.

*Trabalho apresentado na 4a Semana Wanda de Aguiar Horta, 1992.

${ }^{\star *}$ Enfermeira. Assistente do Departamento ENC da Escola de Enfermagem da USP.

${ }^{\star \star \star}$ Enfermeira. Professor Doutor do Departamento ENC da Escola de Enfermagem da USP. 


\section{Introdução}

$\mathrm{Na}$ evolução do saber em enfermagem pudemos caracterizar fases que caminharam da ênfase nos procedimentos técnicos, à busca de princípios científicos que os embasassem; da utilização do método científico como estrutura para a assistência de enfermagem, ate a tentativa de formulação de teorias que oferecessem um referencial a essa assistência.

A utilização do método científico como estrutura de organização para a assistência de enfermagem recebeu entre nós, a partir da década de 60 com os trabalhos de Horta, a denominação de processo de enfermagem.

Este tem sido considerado como uma possibilidade de resposta à sérios questionamentos referentes à qualidade do cuidado e desenvolvimento científico da enfermagem. Com essa visão, incorporamos a exigência de aplicarmos o processo de enfermagem. A prática tem mostrado que ele nada mais do que um instrumento para organizar as etapas necessárias ao cuidado do paciente. As respostas esperadas não vieram e não virão se não buscarmos um conteúdo que atribua validade e direção a esse processo. $A$ proliferação de modelos conceituais no final da década de 60 e no decorrer da de 70 talvez tenha sido estimulada pela necessidade de uma estrutura que fornecesse bases para decidir que dados levantar, o que diagnosticar, sobre o que atuar e o que avaliar².

As fases do processo de enfermagem tem recebido diferentes denominações. Neste trabalho quando usamos os termos avaliação inicial ou coleta de dados do paciente estamos nos referindo à primeira fase desse processo.

Pode-se fazer uma justaposição do mesmo com o método cientifico: as fases de levantamento de dados e de definição do problema no método científico correspondem as de avaliação inicial do paciente e de diagnóstico de enfermagem, sendo que esta última refere-se à definição dos problemas, das necessidades, ou seja, de entidades que o enfermeiro julga que devem ser trabalhadas no âmbito da enfermagem. Essa justaposição entre método científico e processo de enfermagem permite, além do paralelo entre suas etapas, a comparação das características e peculiaridades de cada fase entre eles.

Quando realizamos um estudo é fundamental termos claramente definido o problema em questão, comprometendo-se todas as fases subseqüentes, caso este requisito não seja atendido. Da mesma forma, no processo de enfermagem, se não conseguirmos definir com a maior clareza possível a natureza e a origem das entidades nas quais pretendemos intervir, comprometemos os resultados dos cuidados propostos e realizados.

Com a atenção para não desmerecer a importância das outras fases desse processo e, considerando o seu caráter dinâmico e de inter-relação, a fase de levantamento de dados do paciente e o alicerce no qual se fundamentam as etapas subseqüentes. Como tal, ela tem sido preocupação no ensino e na prática.

Exaustivas modificações de instrumentos para coleta de dados tem sido realizadas, tanto 
em relação a forma quanto ao conteúdo. Essas modificações são, em geral, atribuídas a dificuldades de ordem operacional. No entanto, no nosso entendimento, a origem dessas alterações está na falta de definição e acordo sobre qual seja o ponto a que queremos chegar com os dados levantados.

A coleta de dados ou a avaliação inicial requer do enfermeiro habilidades referentes à abordagem do paciente que envolve técnicas de entrevista e de exame físico, além daquelas necessárias para julgar e decidir os rumos da avaliação numa dada circunstância. Resulta daí a preocupação crescente com a aprendizagem de habilidades que permitam capacitá-lo para o desempenho dessa atividade.

A medida que temos implementado o ensino da avaliação do paciente e que temos elaborado trabalhos, participado de discussões a este respeito, reflexões e questionamentos tem surgido entre os envolvidos com este tema. Esses fatos motivaram a elaboração deste trabalho, que tem a finalidade de discutir aspectos controversos referentes ao ensino da avaliação inicial do paciente e oferecer uma proposta que norteie este conteúdo.

\section{Delimitação do conteúdo da coleta de dados em enfermagem}

Cientes de que, apesar dos esforços, são muitas as questões sobre a avaliação do paciente ainda não respondidas a contento, destacamos como fundamentais a delimitação e a especificidade da coleta de dados em enfermagem.

A especificidade, abrangência e profundidade das informações a serem levantadas não constituem consenso para a profissão e nem tampouco são claros no interior dos diversos segmentos profissionais que se preocupam com essa fase do processo de enfermagem. Cada grupo de ensino, cada instituição de saúde estabelece aspectos baseados em sua própria experiência, crenças e recursos, sem que se consiga clarear as concepções que estão norteando tais aspectos.

Sem essa clareza, o aluno é submetido a diferentes instrumentos de coleta de dados e não tem sequer a possibilidade de identificar motivos razoáveis para tais diferenças. Certamente, essa situação não facilita a aprendizagem e nem o desenvolvimento consistente de sua experiência.

$\mathrm{Na}$ atividade profissional do enfermeiro não está claramente delimitado e nem há consonância sobre quais sejam os fenômenos a que se quer atender. A determinação dos que devem ser privilegiados, o foco que se quer dar as ações, direcionam o tipo de informação a ser levantada.

Entendendo-se foco de ação como entidades, ou situações clínicas nas quais o enfermeiro intervém, acreditamos que deveria existir uma base teórica que lhe desse sustentação. Nota-se, entretanto, uma indefinição, por parte desse profissional, quanto a referida base, que se 
fosse claramente explicitada e suficientemente trabalhada especificaria, restringiria e indicaria os dados a serem coletados. A pouca clareza e a indefinição da base teórica não favorece um acordo sobre que dados da avaliação do paciente são relevantes para a assistência de enfermagem.

Quanto à especificidade do levantamento desses dados pelo enfermeiro, questionase se ele tem característica próprias, específicas do profissional. E possível ou desejável que tivesse?

Algumas reflexões cabem a estas questões. Cremos que na atualidade grande parte da assistência de enfermagem é calcada no modelo médico-alopata. Tem a fisiopatologia como estrutura conceitual e a cura da doença como meta. Assim, com estes referenciais, a coleta de dados realizada pelo enfermeiro e semelhante a do medico, visto que a base te6rica e os objetivos são os mesmos.

Embora não se desconheça que o enfermeiro privilegia no levantamento de dados um ou outro tipo de informação diferentemente do médico, isto não chega a atribuir uma especificidade profissional, a nosso ver. É importante destacar que um raciocínio coerente e consistente para este "privilegiar" um ou outro dado, parece-nos, só nos seria trazido por um foco de ação claramente explicitado.

Seria desejável e possível uma coleta de dados com uma perspectiva específica do profissional enfermeiro? Se nos propusemos a atender fenômenos diferentes da medicina será necessário e natural desenvolver a nossa própria coleta de dados. Talvez cheguemos a criar alguns testes e investigações próprias da enfermagem. Por outro lado, se não houver diferenciação nítida do foco de ação, a especificidade da coleta de dados pelo enfermeiro dilui-se.

\section{Diagnóstico de enfermagem como estrutura referencial para a avaliação inicial do paciente}

A busca de uma estrutura que organizasse a coleta e análise dos dados do paciente pelo enfermeiro e que fosse compartilhada por uma grande parte da categoria profissional, levou-nos a refletir sobre a possibilidade dos diagnósticos de enfermagem servirem como norteadores para a delimitação do conteúdo de ensino da avaliação do paciente. Nesse contexto, os diagnósticos de enfermagem seriam o foco de ação profissional.

O movimento dos diagnósticos de enfermagem ganhou ênfase em 1973 quando realizou-se na América do Norte a II Conferência sobre Diagnósticos de Enfermagem. A intenção era identificar e denominar as situações, entidades ou fenômenos nos quais os enfermeiros intervinham. Nessa II Conferência os participantes apresentaram e denominaram as situações que vivenciavam na prática com pacientes. Foram aceitos como diagnósticos de 
enfermagem as situações que a maioria dos participantes consideraram suficientemente claras para serem testadas clinicamente. Nessa fase foram aceitos cerca de 30 diagnósticos de enfermagem.

Até o momento ocorreram 10 conferências bienais e em 1982 houve a criação da North America Nursing Diagnosis Association (NANDA) que assumiu os trabalhos dessas conferências e que reúne esforços para denominar, classificar, enfim, para o desenvolvimento de todas as questões referentes ao diagnóstico de enfermagem.

Até a $9^{a}$ Conferência, em 1990, foram aceitos 99 diagnósticos de enfermagem e a seguinte definição: diagnóstico de enfermagem e o julgamento clinico das respostas do indivíduo, da família ou da comunidade aos processos vitais ou aos problemas de saúde reais ou potenciais.

Os diagnósticos de enfermagem fornecem a base para a seleção das intervenções de enfermagem, para atingir resultados pelos quais o enfermeiro e responsavel ${ }^{1}$.

Os diagnósticos de enfermagem foram agrupados em 9 categorias denominadas de padrões de respostas humanas, a saber: trocar, comunicar, mover, relacionar, valorar, perceber, sentir, conhecer e escolher. Cada diagnóstico possui definição, listagem de suas características definidoras e de fatores a ele relacionados ${ }^{4}$. A definição procura explicitar o conceito que se tem da situação expressa pela denominação do diagnóstico. As características definidoras são as evidências que o enfermeiro identifica no paciente a partir do levantamento de dados e que pelo seu julgamento interpreta e agrupa. Elas são os fundamentos para a afirmação diagnóstica. Alguns diagnósticos têm características definidoras criticas, isto e, sem a presença delas não se pode afirmar o diagnóstico em questão. Os fatores relacionados são os elementos que contribuem para a ocorrência do diagnóstico. Devem ser investigados pois auxiliam na determinação das intervenções.

$\mathrm{Na}$ proposta do presente trabalho, os diagnósticos de enfermagem e suas características definidoras serviriam de referencial para a delimitação do conteúdo da coleta de dados. Vale dizer, que na América do Norte já há propostas de estruturação da coleta de dados com base nos diagnósticos de enfermagem ${ }^{3}$.

Um questionamento freqüente relacionado a coleta de dados e a dúvida sobre o que se faz com as informações levantadas. O diagnóstico de enfermagem justifica e atribui-Ihes significado, respondendo, em parte, a questão de: para que são coletadas?

Ainda, ao agrupar, organizar, relacionar e julgar problemas, aqui entendidos como sinais e sintomas, a compreensão mais globalizante do paciente seria facilitada o que, por sua vez, possibilitaria intervenções mais fundamentadas. Também a padronização da linguagem proposta pelos diagnósticos de enfermagem facilita a comunicação dos resultados obtidos, a partir do julgamento dos dados coletados.

Tradicionalmente, o ensino da coleta de dados do paciente pelo enfermeiro tem preconizado, nos seus aspectos biológicos, uma análise seqüencial dos sistemas orgânicos adotando-se geralmente a direção céfalo-caudal. Aspectos de ordem psicológica, social e espiritual também são incluídos neste ensino. 
O que podemos depreender do que temos visto até o momento no ensino da avaliação inicial de enfermagem? Um dos grandes problemas é a delimitação do conteúdo do exame físico e do encaminhamento das entrevistas. 0 aluno de enfermagem deve aprender a detectar hepatoesplenomegalia pela palpação? Deve saber reconhecer sopros pela ausculta cardíaca? e a ausculta pulmonar? Quais problemas psicológicos, sociais e espirituais ele deve aprender a detectar?

Essas dúvidas surgem em conseqüência do questionamento se é ou não da competência do enfermeiro detectar esses problemas e em caso positivo, qual a ação de enfermagem que justificaria tais buscas.

Em grupos de estudo sobre a avaliação inicial de enfermagem estas e outras questões sempre surgem como dignas de uma reflexão em conjunto.

Utilizar diagnósticos de enfermagem como estrutura referencial para o levantamento de dados do paciente, não nega os aspectos envolvidos no ensino da avaliação inicial até então desenvolvido. As técnicas de entrevista, a busca de dados nos exames subsidiários e os métodos de exame físico tradicionalmente ensinados aos alunos continuam tendo o seu valor.

A contribuição em adotar o diagnóstico de enfermagem como referência, será de encontrar nas características definidoras parâmetros que colocarão limites até onde deve chegar a avaliação que esta diretamente relacionada a assistência de enfermagem.

Por exemplo, no que se refere a uma das dúvidas anteriormente citadas sobre a ausculta pulmonar, se tomarmos o diagnóstico de enfermagem como referência, conclui-se claramente que é um procedimento que deve ser ensinado ao aluno de graduação pois a presença de ruídos adventícios e uma característica definidora do diagnóstico de eliminação traqueobronquica ineficaz.

Percebe-se também que ao adotar o diagnóstico de enfermagem como referência, itens da avaliação de enfermagem que habitualmente não são levantados seriam acrescentados ao ensino, especialmente nas situações referentes a outras áreas que não a biológica. Por exemplo, para se formular o diagnóstico de conflito de decisão e necessário que se obtenham informações do paciente que envolvem características definidoras como: verbalização de incertezas a respeito das escolhas, verbalização de conseqüências indesejadas, ao serem consideradas ações alternativas, vacilação entre escolhas alternativas, adiamento de decisão.

A utilização de diagnósticos de enfermagem relativos a aspectos sociais e emocionais, de uma certa forma, clareia qual seja o âmbito da enfermagem nessa área. Uma vez aceitos tais diagnósticos como relevantes para o cuidado de enfermagem, necessitaríamos nos capacitar, de forma direcionada, tanto para identificá-los, quanto para neles intervirmos. Eles localizariam o fazer da enfermagem referente a um âmbito que, no discurso, dizemos que abordamos, mas que, na prática, é totalmente amorfo e calcado no senso comum. 


\subsection{Limitações da utilização dos diagnósticos de enfermagem como estrutura referencial para a coleta de dados}

No Brasil, só recentemente os diagnósticos de enfermagem têm sido estudados e divulgados. Assim, o desconhecimento sobre o assunto é um fator limitante a sua utilização como referencial para o levantamento de dados do paciente. Além disso, na tradução dos diagnósticos de enfermagem os termos nem sempre são equivalentes a nossa linguagem corrente, o que acarreta dificuldades de interpretação e utilização.

Os diagnósticos de enfermagem estruturam e atribuem denominação às entidades, fenômenos e situações com os quais os enfermeiros tradicional e contemporaneamente têm se proposto a trabalhar, mas não explicitam uma base teórica. Na maioria das vezes, fica subentendido que o marco teórico e a fisiologia, que tem sido um referencial indissociável do cuidar em enfermagem. Já em outros casos, não se identifica a base teórica, embora esta pareça estar calcada na psicologia e na sociologia.

Por terem sido elaborados a partir de uma visão e prática de enfermeiros de uma cultura diferente da nossa, a necessidade de validação desses diagnósticos para nossa realidade também pode ser considerada um fator limitante.

Ainda, a utilização dos diagnósticos de enfermagem como referencial para o levantamento de dados, implica em reformular e adequar o conteúdo tradicional de ensino de coleta de dados à luz deste novo referencial.

\section{Considerações finais}

O diagnóstico de enfermagem e um elemento que preenche a lacuna entre a coleta de dados e o planejamento do cuidado. Assim, da mesma forma que a coleta de dados, ele não possui uma finalidade em si mesmo. Embora ambos subsidiem as etapas posteriores do processo de enfermagem, e nas intervenções e avaliação dos seus resultados que culmina o processo de cuidar.

A abrangência dos diagnósticos de enfermagem e vasta, com grandes vantagens de clarear os fenômenos, os problemas de enfermagem e, sem duvida, ajudam a organizar a delimitar a coleta de dados. No entanto, coloca-nos diante do quanto estamos carentes em relação às intervenções de enfermagem, especial mente nas situações referentes às outras áreas que não a biológica.

PIMENTA, C.A. de M., CRUZ, D.A.L..M. de, ARAUJO, T.L.. de, GRAZIANO, K.U., KIMURA, M. MIYADAHIRA, A.M.K. Patient teaching assessment: propose based on nursing diagnosis defining the content about nursing assessment. 
The nursing care is based on the nursing assessment. In the nurse's professional activity there aren't clarity and consensus about the clinical entities, problems or phenomenous that nurses intended to care. Difficulties in deciding what should be collected are determined by this indefinition, that it is also present in nursing graduate courses. In this article the authors discuss that the Nursing Diagnosis can be the framework for the nursing assessment.

UNITERMS: Assessment, nursing diagnosis, teaching

PIMENTA, C.A. de M., CRUZ; D.A.L.M. de, ARAUJO, T.L. de, GRAZIANO, K.U., KIMURA, M., MIYADAHIRA, A.M.K. La enseñanza de la evaluación del paciente: propuesta del diagnóstico de enfermería como estructura referencial.

La recolección de datos es la base sobre la cual se fundamenta la atención de enfermería. En la actividad profesional del enfermero no están claramente delimitados cuales son las entidades clínicas, problemas o fenómenos que se quieren asistir, ni tampoco existe consenso sobre ellos. Eso trae dificultades para definir cuales datos se deben recolectar y esta indefinición se presenta en la enseñanza de la evoluación del paciente. Estimando que la determinación de los fenómenos que hay que privilegiar direcciona el tipo de dato que se va a recolectar, las autoras proponen el diagnóstico de enfermería como estructura referencial para la recolección de datos del paciente.

UNITERMOS: evaluación, diagnóstico de enfermería, enseñanza

\section{REFERÊNCIAS BIBLIOGRÁFICAS}

01. FARIAS, J.N. et al. Diagnóstico de enfermagem: uma abordagem conceitual e prática. João Pessoa: Santa Maria, 1990.

02. GORDON, M. Nursing diagnosis: process and application. 2. ed. New York: McGraw Hill, 1987.

03. GUZZETTA, C. E. et al. Clinical assessment tools for use with nursing diagnoses. St. Louis: Mosby, 1989.

04. TAXONOMY, I. Revised 1989: with official diagnostic categories. Saint Louis: North American Nursing Diagnosis Association, 1989. 